Whatever doubts one may have concerning the use to which the book is to be put, any work that may encourage biologists to take an interest in evolution and the history of its theory is welcome, and this book should certainly do that. It is especially valuable that the "Autobiography" should be reprinted; this has not been done, to my knowledge, since Darwin's "Life and Letters" were published by his son in 1887 .

G. S. Carter

\section{THE MECHANISM OF INSECT FLIGHT}

Insect Flight

By Dr. J. W. S. Pringle. (Cambridge Monographs in Experimental Biology, No. 9.) Pp. viii +133. (Cambridge: At the University Press, 1957.) $15 s$. net.

THE problem of how insects fly has interested biologists for a very long time. This interest has been intensively revived, partly as the result of the development of new techniques, since the War. Half the references on which "Insect Flight" is based are from the past ten years, showing new productivity which would be sufficient resson in itself for a monograph. But the immediate reasons for its appearance are twofold. One is the realization (by Boettiger and Pringle, independently) that in insect flight muscle, particularly that of the higher orders of insects, there are peculiar physiological mechanisms of considerable interest. The interpretation of these may throw new light on problems of the functioning of muscle tissue in general. The other is the recent publication of several papers which describe a very thorough investigation of the flight of locusts made by T. Weis-Fogh, a brilliant pupil of the late August Krogh. This work made the minimum of assumptions, utilized exact methods and rigorous analysis and thereby greatly illuminated the whole problem. These matters are dealt with in the monograph. At every stage in the presentation new lines of development are made apparent. In particular, the elucidation of the special physiological problems of the flight muscles offers a rewarding challenge, and the aerodynamic problems which have been overcome by extremely small flying insects require clarification.

The monograph illustrates well the newer approach to problems of experimental biology, in which the artificial barriers between collateral disciplines are broken down in the interest of solving a single functional problem. The anatomy, fine-structure, cytology, biochemistry, sensory and motor physiology and flight dynamics of the relevant parts are all given careful treatment. Critics of this approach will have to look hard for traces of superficiality. It is noteworthy in this connexion that most of the recent advances reported have come from zoologists who, like Weis-Fogh, have mastered other disciplines with no other end in view than bringing their techniques and principles to bear on the insect problem. Insect flight has in the past attracted a lot of attention of the arm-chair variety, with the result that it suffers from a number of unwarranted simplifications. Now it has advanced far beyond the string-and-sealingwax stage and is being placed on a firm foundation of observation and theory.

The text is extremely well illustrated with 52 textfigures including several original drawings. All pay tribute to Dr. Pringle's superb draughtsmanship and unique sense of emphasis. The book suffers from only one fault- - that of being difficult to read; but this only reflects the complexity of the mechanisms of insect flight and the inevitable consequences of the distillation of information.

It is a pity that the important work of Rodendorf (1951) on dipteran flight was not covered. Also the observations of Larssen on the thoracic muscles of gyrinid beetles, some of which fly although completely lacking dorsal longitudinal muscles. Pringle notes that the dorsal longitudinal muscles of some beetles are reduced in size. Their function is taken over by the basalar and subelar muscles. (I am indebted to Mr. R. A. Crowson for directing my attention to these papers.)

"Insect Flight" is a book in which many physiologists, biochemists and biophysicists as well as zoologists should find much to interest them. It has the advantage shared with other books in the series of being at a price which one can afford and of a length which permits reading from cover to cover.

Gratam Hoyle

\section{FISH PHYSIOLOGY}

\section{The Physiology of Fishes}

Edited by Margaret E. Brown. Vol. 1 : Metabolism. Pp. xiii +447 . 12 dollars. Vol. 2 : Behavior. Pp. $\mathrm{xi}+526$. 14 dollars. (New York : Academic Press, Inc., 1957.)

The Physiology of the Pituitary Gland of Fishes

By Grace E. Pickford and James W. Atz. Pp. xxiii + 613. (Now York: Now York Zoological Society, 1957.) 6 dollars.

R. MARGARET BROWN does not tell us how she came to have the idea of asking a number of authors to write upon different aspects of the physiology of fishes. It was a very good idea, and the result has been two volumes that will be of value and delight to many general zoologists as well as to those interested especially in fishes and fisheries research, to whom she says they are specially directed. Although there are no close links between the various sections, there is evidence that Dr. Brown has unobtrusively played a considerable part in editing the whole. In particular, she has herself set for esch author the extent of his contribution-an excellent plan, which has ensured special emphasis on fields often neglected or of special interest becsuse of recent work. Dr. Brown's own article on "Experimental Studies on Growth" is a good example. She has succeeded in collecting many fascinating facts about the determination of the age and growth of fishes and relating these to general biological problems.

Inevitably, any book that deals with the physiology of an arbitrarily chosen group of vertebrates will seem in some respects disjointed. One regrets particularly that neither amphioxus nor ascidians have been considered to be 'fishes'. Without them the discussions of the evolution of, for exemple, digestion and the endocrines inevitably lose some of their interest-though both remain fascinating enough.

The depth of the treatment and extent of literature quoted vary somewhat. There are more than 125 references on the swim bladder, but only eight on colour changes. Generally speaking, the work will 